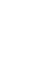

\section{ErbB-2 nuclear function in breast cancer growth, metastasis and resistance to therapy}

\author{
Patricia V Elizalde, Rosalía I Cordo Russo, Maria F Chervo and Roxana Schillaci \\ Laboratory of Molecular Mechanisms of Carcinogenesis, Instituto de Biología y Medicina Experimental, \\ CONICET, Buenos Aires, Argentina
}

Correspondence should be addressed to $\mathrm{P} V$ Elizalde Email patriciaelizalde@ibyme. conicet.gov.ar

\begin{abstract}
Approximately $15-20 \%$ of breast cancers (BC) show either membrane overexpression of ErbB-2 (MErbB-2), a member of the ErbBs family of receptor tyrosine kinases, or ERBB2 gene amplification. Until the development of MErbB-2-targeted therapies, this BC subtype, called ErbB-2-positive, was associated with increased metastatic potential and poor prognosis. Although these therapies have significantly improved overall survival and cure rates, resistance to available drugs is still a major clinical issue. In its classical mechanism, MErbB-2 activates downstream signaling cascades, which transduce its effects in BC. The fact that ErbB-2 is also present in the nucleus of BC cells was discovered over twenty years ago. Also, compelling evidence revealed a non-canonical function of nuclear ErbB-2 as a transcriptional regulator. As a deeper understanding of nuclear ErbB-2 actions would be crucial to the disclosure of its role as a biomarker and a target of therapy in $B C$, we will here review its function in $B C$, in particular, its role in growth, metastatic spreading and response to currently available MErbB-2-positive BC therapies.
\end{abstract}

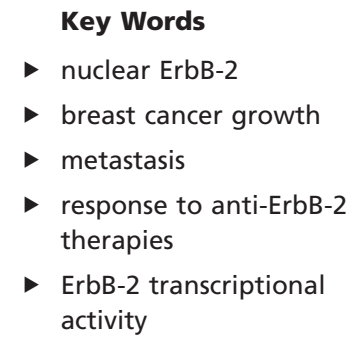

Endocrine-Related Cancer (2016) 23, T243-T257

\section{Introduction}

Breast cancer (BC) is the most frequently diagnosed cancer in women, with an estimated 1.5 million new cases annually. With 500,000 deaths per year worldwide, it is the prevalent cause of death by cancer in women both in the industrialized and the developing world (Maxmen 2012). BC is a complex and heterogeneous disease, comprising multiple tumor subtypes associated with distinct histological patterns and different biological features and clinical behaviors. According to BC molecular classification, the subtype overexpressing ErbB-2 in the cytoplasmic membrane (MErbB-2), a member of the ErbBs family of receptor tyrosine kinases (RTKs), or showing ErbB-2 gene (ERBB2) amplification, is called ErbB-2-positive (Slamon et al. 1989, Ross et al. 2009).
Decades of research since the discovery of MErbB-2 role as a potent inducer of $\mathrm{BC}$ growth in vitro and in preclinical models demonstrated that the ErbB-2-positive subtype is associated with high incidence of metastasis in BC patients and revealed MErbB-2 overexpression or ERBB2 gene amplification as prognostic biomarkers of the course of the disease (Slamon et al. 1989, Henderson \& Patek 1998, Ross et al. 2009). Interestingly, EGF-R, another member of the ErbBs family, was detected in the cell nucleus as early as in 1984 , but with no description of its role in that location (Gusterson et al. 1984). It was only ten years later that the pioneering work by Hung and coworkers demonstrated that NIH cells transfected with the rat variant of ErbB-2 (p185 ${ }^{\mathrm{neu}}$ ) showed strong $\mathrm{p} 185^{\mathrm{neu}}$ nuclear presence

This paper is part of a thematic review section on hormone-dependent cancers. The Guest Editor for this section was Wayne Tilley. 
(Xie \& Hung 1994). Remarkably intriguing were also their findings revealing that the carboxyl terminus of p185neu displays transactivation activity when tested in a GAL4reporter assay. More than twenty years have gone by since this initial discovery, which was followed by numerous other findings identifying nuclear presence of as many as 18 distinct RTKs so far (reviewed in Carpenter \& Liao 2013). We have come a long way since the days when the notion of ErbBs in the nucleus was so utterly challenging that it was regarded as either 'ridiculous or sublime' (Waugh $\&$ Hsuan 2001). Indeed, compelling evidence has shown ErbB-2 localization in the nucleus of BC cells, where it functions as a transcriptional regulator (Tan et al. 2002, Wang et al. 2004, Kim et al. 2009, Beguelin et al. 2010, Li et al. 2011, 2012, Diaz Flaque et al. 2013a,b, Cordo Russo et al. 2015, Venturutti et al. 2015). However, the role of nuclear ErbB-2 (NErbB-2) as a biomarker and a target of therapy in $\mathrm{BC}$ is still unexplored. Here, we will review the function of nuclear ErbB-2 in BC, in particular, regarding tumor growth, metastatic spreading and response to currently available BC therapies.

\section{Studies on ErbB-2 structure}

ErbB-2, also called human epidermal growth factor 2 (HER2) and Neu, is a member of the ErbBs or type I receptor tyrosine kinase (RTK) family, which also includes the epidermal growth factor receptor (EGF-R/ErbB-1), ErbB-3 and ErbB-4. ERBB2 gene is localized on the long arm of chromosome 17 (Popescu et al. 1989). Throughout time, this $185 \mathrm{kDa}$ transmembrane glycoprotein was given different names as it was being identified in different species. It was called Neu because it was initially identified in ethylnitrosourea-induced rat neuroblastomas (Schechter et al. 1984, 1985, Bargmann et al. 1986). The human gene, on the other hand, was designated as ErbB-2/HER2 for its strong homology with ErbB (avian erythroblastosis oncogene $\mathrm{B}$ ), the oncogene later found to encode the EGF-R/ErbB-1 (Semba et al. 1985). Cloning of the gene showed that, indeed, rat Neu and human ErbB-2/ HER2 are encoded by orthologs (Yamamoto et al. 1986). Members of the ErbBs family are transmembrane RTKs with a large glycosylated extracellular portion containing four domains (I-IV), a single membrane-spanning region and a cytoplasmic tyrosine kinase domain. Extracellular domains II and IV are cysteine-rich regions, which display conserved number and spacing of cysteine residues among the members of the family. Domains I and III participate in ligand binding. The intracellular portion of ErbB receptors is composed of a juxtamembrane domain, the kinase domain and a carboxyl (C)-terminal tail, which contains several tyrosine residues that play a key role in the transduction of ErbBs biological effects (reviewed in Riese \& Stern 1998, Olayioye et al. 2000, Yarden \& Sliwkowski 2001, Burgess 2008) (Fig. 1 depicts the structure of ErbB-2).

More than twenty years have passed since the discovery that, in addition to their canonical subcellular localization in the cytoplasmic membrane, ErbB receptors are located in the cell nucleus, where they regulate multiple biological functions (reviewed in Lee et al. 2015). The series of compelling findings revealing nuclear ErbBs presence (reviewed in Wang \& Hung 2012) stimulated a most exciting research into the mechanisms of ErbBs nuclear migration and into the identification of the ErbBs domains involved in both trafficking from the cytoplasmic

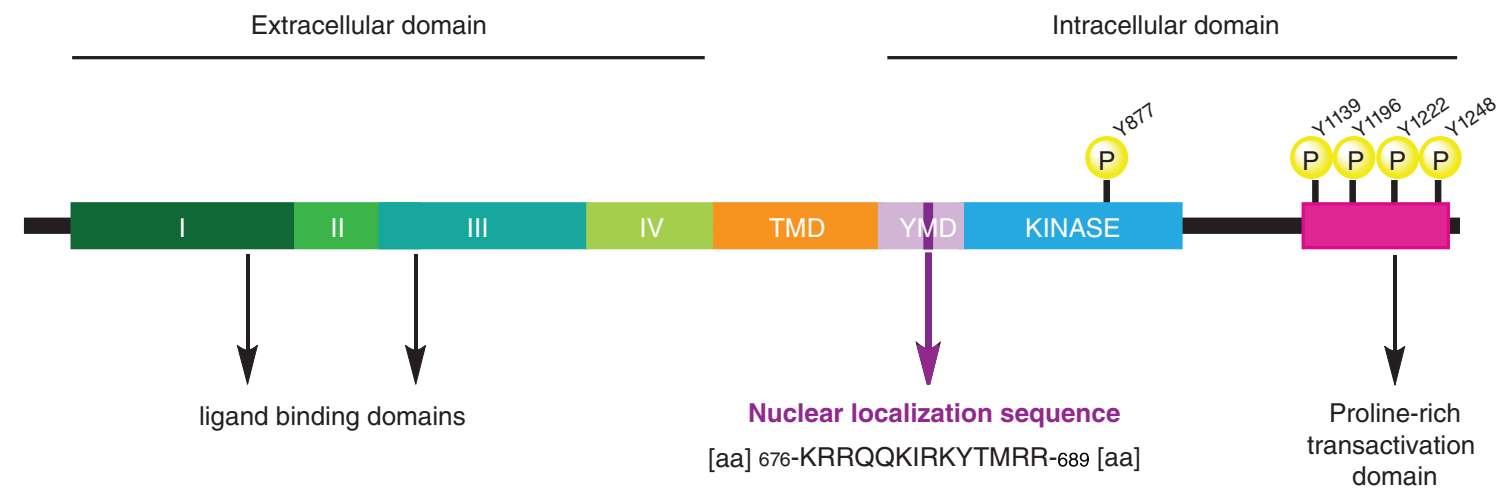

Figure 1

ErbB-2 structure. Regions that are relevant to ErbB-2 function are indicated schematically. The extracellular portion is composed by 4 domains (I-IV). ErbB-2 contains a transmembrane domain (TMD) and a juxtamembrane domain (YMD), which encloses the nuclear localization sequence (NLS, purple). The intracellular domain includes the kinase domain (blue) and a proline-rich transactivation domain near the carboxy-terminus (pink). The major phosphorylation sites are indicated (yellow circles). 
membrane to the nucleus and in ErbBs nuclear function as transcriptional activators. A nuclear localization sequence (NLS) was identified in all ErbBs (Offterdinger et al. 2002, Wang et al. 2004, Williams et al. 2004, Lo et al. 2005). The NLS is located adjacent to the transmembrane domain in ErbB-2 and contains three clusters of basic amino acids (676-KRRQQKIRKYTMRR-689) (Chen et al. 2005, Giri et al. 2005, Hsu \& Hung 2007) (Fig. 1). This tri-partite NLS is conserved among the members of the ErbBs family (reviewed in Lee et al. 2015). Furthermore, functional transactivation domains were mapped at the C-terminal acidic region of EGF-R, ErbB-2, ErbB-3 and ErbB-4 (Xie \& Hung 1994, Lin et al. 2001, Ni et al. 2001, Wang et al. 2004, Brand et al. 2013). Figure 1 shows the proline-rich transactivation domain of ErbB-2. To date, no DNA-binding domain has been identified for the members of the ErbBs family. Therefore, it has been proposed that other transcription factors with DNA binding ability may cooperate with ErbBs to regulate gene expression.

\section{ErbB-2 canonical mechanism of action}

A large number of ligands for the ErbBs have been described. They include eight ligands for EGF-R (reviewed in Riese \& Stern 1998, Burgess 2008, Schneider \& Wolf 2009) and all isoforms of Neu differentiation factor/ heregulins (HRG), which bind to ErbB-3 and ErbB-4 (Tzahar et al. 1996). EGF-R and ErbB-2 act as HRG co-receptors (Tzahar et al. 1996). Interestingly, ErbB-2 is an orphan receptor. The extracellular domain of ErbB-2 differs from that of the other ErbBs in that it constitutively adopts an open conformation, which exposes the dimerization loop in domain II (Cho et al. 2003, Garrett et al. 2003). This unique ErbB-2 structure helps to explain the fact that despite the absence of a known ligand that binds ErbB-2 directly, this receptor participates in an extensive network of ligand-induced formation of ErbBs dimers (Graus-Porta et al. 1997). In BC cells overexpressing MErbB-2, it also assembles homodimers and heterodimers in the absence of ligand (Landgraf 2007, Tao \& Maruyama 2008). As a direct consequence of ligand binding to the extracellular domain of the ErbBs family, receptor dimers are formed and their intrinsic kinase activity is stimulated, which leads to the phosphorylation of tyrosine residues in the intracellular domain of receptors. These phosphorylated tyrosine residues link ErbBs to several signaling pathways, the classic transduction mechanism of ErbBs biological effects in BC. ErbB-3 is a unique member of this family because it displays impaired tyrosine kinase activity (Sierke et al.
1997, Jura et al. 2009). Among ErbB-2-activated cascades, the best characterized are the p42/p44 mitogen-activated protein kinases (MAPKs) and the phosphatidylinositol 3-kinase (PI3K)/AKT pathways (reviewed in Riese \& Stern 1998, Olayioye et al. 2000, Yarden \& Sliwkowski 2001, Burgess 2008). Accumulating evidence showed that ErbB-2 also activates the signal transducer and activator of transcription 3 (Stat3) pathway, which acts as a downstream effector of ErbB-2-induced initiation and metastatic dissemination of BC (Proietti et al. 2009, Ranger et al. 2009, Barbieri et al. 2010a,b). Src tyrosine kinase (reviewed in Ishizawar \& Parsons 2004), and the serine/threonine kinase mammalian target of rapamycin (mTOR), which is activated downstream of PI3K-AKT, are also stimulated by ErbB-2 (reviewed in Mayer \& Arteaga 2016).

\section{ErbB-2 and breast cancer}

Approximately $15-20 \%$ of all diagnosed breast tumors belong to the ErbB-2-positive subtype (Slamon et al. 1989, Ross et al. 2009). Until the development of antiMErbB-2-targeted therapies, this subtype was associated with higher metastatic potential and poor prognosis in $\mathrm{BC}$ patients with node-positive and -negative tumors (Slamon et al. 1989, Henderson \& Patek 1998, Ross et al. 2009). Notably, the overall survival (OS) of metastatic $\mathrm{BC}$ patients and the cure rate in the adjuvant setting improved significantly after the development of said therapies (Slamon et al. 2001, Romond et al. 2005). Current therapeutic options for patients whose tumors overexpress MErbB-2 include monoclonal antibodies (trastuzumab and pertuzumab), tyrosine kinase inhibitors (lapatinib) and trastuzumab-DM1, an antibody-drug conjugate. Trastuzumab (TZ) was the first anti-ErbB-2 therapy approved for metastatic and early-stage BC. These strategies are being used in different combinations, along also with chemotherapy in the neoadjuvant, adjuvant and metastatic settings (for review see Patel et al. 2014). Despite a significant clinical response to trastuzumab (TZ), around $40-60 \%$ of patients with ErbB-2-positive metastatic $\mathrm{BC}$ do not respond to $\mathrm{TZ}$, showing either de novo or acquired resistance (Slamon et al. 2001, Esteva et al. 2002). Although lapatinib provides clinical benefit to a subset of patients progressing on $\mathrm{TZ}$, less than $25 \%$ achieve an objective response, and the majority eventually develop acquired lapatinib resistance (Geyer et al. 2006). These data highlight that resistance to available drugs is a major clinical issue (Patel et al. 2014). 
Multiple mechanisms were found to cause TZ resistance in $\mathrm{BC}$ cells and in preclinical models, such as expression of constitutively active truncated forms of ErbB-2, presence of ligand-induced ErbB-2/ErbB-3 dimers and ErbB-2/ insulin-like growth factor receptor I (IGF1-R) dimerization (reviewed in Esteva et al. 2010). Hyperactivation of the PI3K/AKT pathway is the best acknowledged alteration in downstream signaling associated with $\mathrm{TZ}$ resistance. It also plays a role in the lack of response to lapatinib (Garrett et al. 2011). A plethora of clinical trials in patients with refractory ErbB-2-positive metastatic $\mathrm{BC}$ are assessing the efficacy of novel treatments with afatinib, an irreversible EGF-R and ErbB-2 tyrosine kinase inhibitor; neratinib, an inhibitor of ErbB-2, EGF-R and ErbB-4 activation; PI3K/ AKT inhibitors; mTOR inhibitors; anti-IGF-IR antibodies; and inhibitors of heat shock protein 90 (reviewed in Stern 2012, Singh et al. 2014).

\section{Truncated ErbB-2 variants in BC}

Proteolytic cleavage of ErbB-2 in BC cells has long been reported (Lin \& Clinton 1991, Pupa et al. 1993). Matrix metalloproteases (MMP), such as MMP-1 (Codony-Servat et al. 1999) and ADAM10, members of the metalloproteasedesintegrin family (Liu et al. 2006), have been found to participate in ErbB-2 cleavage within the extracellular juxtamembrane region. This results in the shedding of the ErbB-2 extracellular domain (ECD), leaving a p95 fragment that contains the transmembrane and intracellular domains, referred to as 648-CFT (carboxyterminal fragment). Moreover, alternative initiation of translation from two methionine residues (611 and 687), which are located before and after the transmembrane domain, respectively, gives rise to other p95ErbB-2 variants, named 611-CFT and 687-CFT (Anido et al. 2006). These ErbB-2 truncated forms, collectively referred to as p95ErbB-2, have been shown to induce growth of BC xenografts in nude mice (Anido et al. 2006, Scaltriti et al. 2007). They are also frequently found in BC cell lines and in human mammary tumors, where they may even constitute the major ErbB-2 species and are associated with nodal metastasis (Molina et al. 2002). Expression of wild-type 611-CTF in the mouse mammary gland led to the development of aggressive tumors (Pedersen et al. 2009). In addition, p95ErbB- 2 variants cause TZ resistance (Anido et al. 2006, Scaltriti et al. 2007). Resistance to the antiestrogen toremifene was also associated with the generation of p95ErbB-2 variants (Warri et al. 1996). The molecular mechanisms through which p95ErbB-2 variants control ErbB-2-positive BC metastatic spreading and response to anti-MErbB-2 therapies remain poorly explored. It has been demonstrated that transmembrane 611-CTF, which is able to activate p42/p44 MAPKs and AKT pathways, phosphorylates the cytoskeleton-binding protein cortactin, which is involved in 611-CTF induction of $\mathrm{BC}$ cells migration and metastasis (Garcia-Castillo et al. 2009). Moreover, a transcriptomic analysis revealed that 611-CTF controls the expression of genes that are associated with metastasis, including the receptor tyrosine kinases MET and EPHA2, matrix metalloproteinase 1, interleukin 11, angiopoietin-like 4 and several integrins (Pedersen et al. 2009).

\section{Nuclear ErbB-2 action in breast cancer}

Numerous findings strongly demonstrated that fulllength ErbB-2 is present in the nucleus of BC cells, where it binds promoters/enhancers of target genes to regulate biological responses in BC (Tan et al. 2002, Wang et al. 2004, Kim et al. 2009, Beguelin et al. 2010, Li et al. 2011, 2012, Diaz Flaque et al. 2013a,b, Cordo Russo et al. 2015, Venturutti et al. 2015). Importantly, the development of more sophisticated techniques to study protein trafficking from the cytoplasmic membrane to different subcellular compartments, allowed further understanding of the mechanism involved in ErbB-2 nuclear translocation. It has been demonstrated that ErbB-2 is internalized from the cell membrane by endocytic internalization and endosomal sorting (Giri et al. 2005, Wang et al. 2010a). During the cytoplasmic-nuclear transport, ErbB-2 associates with importin $\beta 1$, a member of the nuclear transport machinery, via ErbB-2 NLS. The ErbB-2/importin $\beta 1$ complex then interacts with the nuclear pore protein Nup358, which results in ErbB-2 nuclear translocation (Giri et al. 2005). These steps are in accordance with well-acknowledged mechanisms of intracellular trafficking (Sandvig \& van Deurs 2002, Giri et al. 2005, Bonifacino \& Rojas 2006, Wang et al. 2010a, 2012). However, it was still necessary to explain how intact ErbB-2 could be extracted from a membrane bilayer, either at the cell surface or within an intracellular compartment like the endosome, to allow its translocation to the nucleus as a non-membrane localized molecule. That is indeed how intact transmembrane proteins are extracted from the endoplasmic reticulum (ER) to be carried into the cytoplasm. This mechanism is the ER-associated degradation (ERAD) system, which detects mal-folded proteins in the ER and carries them to the cytoplasm, where they are ubiquitinated and degraded 
(Tsai et al. 2002). A series of studies revealed that for EGF-R and ErbB-2, the Sec61 translocon located in the ER, which is part of the ERAD pathway, mediates retrotranslocation of said receptors to the cytoplasm and their import to the nucleus. Furthermore, a membrane-bound mechanism of EGF-R and ErbB-2 trafficking from the cell surface to the nucleus, named INTERNET (integral trafficking from the ER to the nuclear envelope transport) has been identified (Wang et al. 2010b, 2012). Importin $\beta 1$ and the Sec61 translocon also participate in this mechanism, where membrane-embedded full-length ErbBs are transported to the nucleus (Wang et al. 2010b, 2012). Figure 2 illustrates the proposed trafficking pathway of full-length ErbB-2 to the nucleus, induced by either HRG binding to ErbB-3,

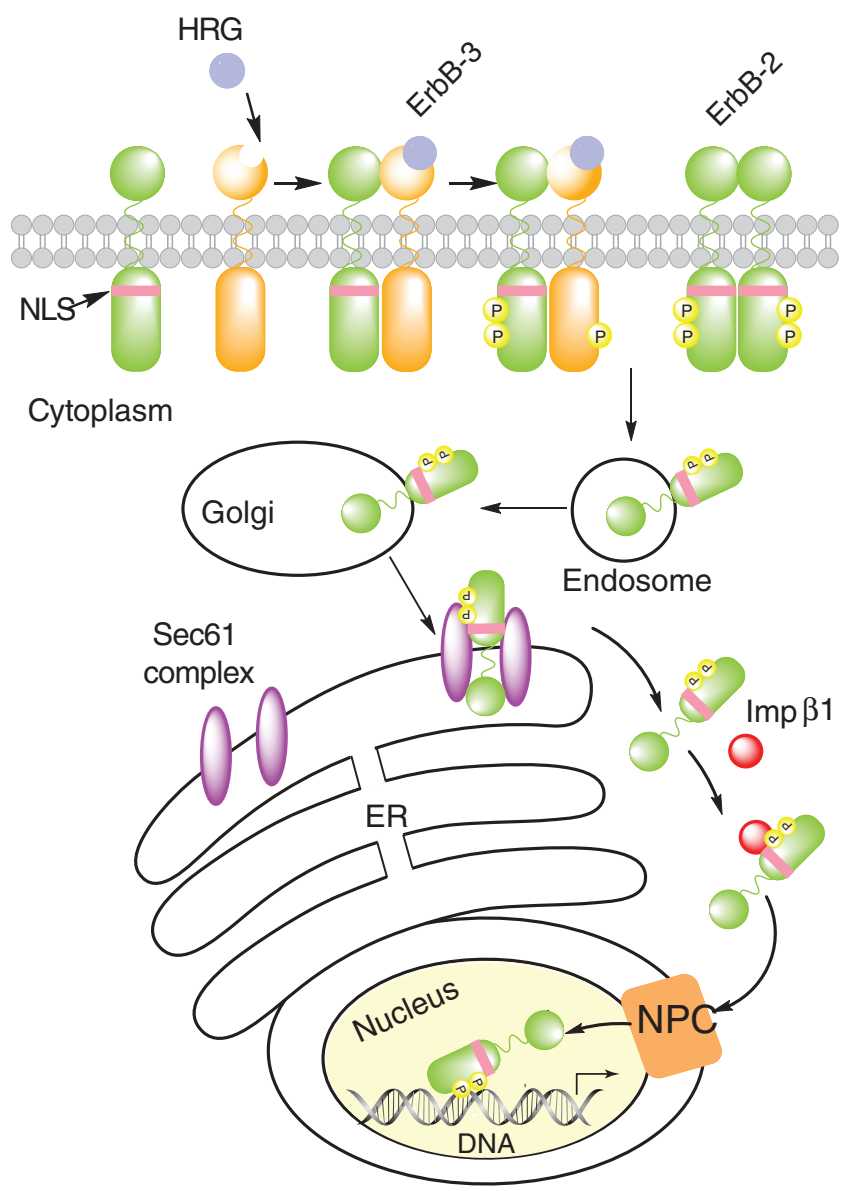

Figure 2

Proposed model of ligand (HRG)-induced and constitutive ErbB-2 nuclear transport from the cell surface to the nucleus. In this model, the Sec61 translocon, part of the ERAD pathway, associates with ErbB-2 at the endoplasmic reticulum (ER) and extracts full-length ErbB-2 from the membrane bilayer allowing its interaction with importin $\beta 1$ (Imp $\beta 1$ ). The ErbB-2/importin $\beta 1$ complex then interacts with the nuclear pore protein Nup358, a member of the nuclear pore complex (NPC), which results in ErbB-2 nuclear translocation. NLS, nuclear localization sequence. which leads to the formation of ErbB-2/ErbB-3 dimers and ErbB-2 activation or by constitutive ErbB- 2 activation induced by the formation of ErbB-2 homodimers. The mechanisms of ErbB-2 nuclear translocation has been extensively reviewed elsewhere (Giri et al. 2005, Wang et al. 2010b, Wang \& Hung 2012, Carpenter \& Liao 2013, Bertelsen \& Stang 2014, Chen \& Hung 2015). In spite of all these findings highlighting nuclear ErbB-2's key role in $\mathrm{BC}$ and providing a mechanistic explanation for its nuclear trafficking, the clinical significance of nuclear ErbB-2 remains almost unexplored. Furthermore, to the best of our knowledge and for reasons that remain unclear, there is no single drug designed to target the function of nuclear ErbB-2, which plays a major role in BC.

\section{Nuclear ErbB-2 in breast cancer proliferation and metastasis}

The dogma of ErbB-2 mechanism of action in $\mathrm{BC}$ has been challenged by Hung and coworkers who demonstrated that in MErbB-2-overexpressing BC cells, ErbB-2 migrates to the nuclear compartment where it binds to the DNA at specific sequences, which they named HER-2-associated sequences (HASs) (Wang et al. 2004). In this startling work, the full-length ErbB-2 protein was found in the nucleus. Furthermore, ErbB-2 tyrosine phosphorylation was required for its nuclear localization. Cyclooxygenase- 2 (COX-2) was revealed in the said study as the first gene whose expression was modulated via the role of ErbB-2 as a transcription factor (TF) (Wang et al. 2004). The association of ErbB-2 with the COX-2 promoter at the HASbinding site was detected in $\mathrm{BC}$ cell lines overexpressing ErbB-2, as well as in ErbB-2-positive human primary breast tumors (Wang et al. 2004). Inhibition of COX-2 activity in MCF-7 BC cells engineered to overexpress ErbB-2, and in parental MCF-7 cells, which display low endogenous levels of MErbB-2, had no effect on the proliferation of the latter, but suppressed the invasive activity of ErbB-2-overexpressing MCF-7 cells (Wang et al. 2004), indicating that nuclear ErbB-2's function as a TF may play a role in BC metastasis. These authors also found functional recruitment of ErbB- 2 at the HAS sites of the PRPK (p53-related protein kinase) (Abe et al. 2001) promoter, which depends on ErbB-2-intact tyrosine kinase activity. As ErbBs lack a putative DNA-binding domain, it was proposed that they exert their nuclear function as coactivators of other TFs, which bind DNA directly. A role of nuclear ErbB-2 as a transcriptional coactivator was indeed revealed in $\mathrm{BC}$ models, which express estrogen

Published by Bioscientifica Ltd. 
receptor (ER) and progesterone receptor (PR) - members of the steroid receptor superfamily - and also overexpress or show moderate levels of MErbB-2 (Beguelin et al. 2010). In these models, the presence of bidirectional interactions between PR and MErbB-2 classical signaling pathways had long been identified. On the one hand, PR was found to activate the HRG/ErbB-2 signaling pathway (Balana et al. 1999). On the other hand, it was reported that HRG induces PR transcriptional activation in breast tumors through a mechanism that requires functional ErbB-2 (Labriola et al. 2003). Stat3 was revealed as the nodal convergence point between PR and HRG/ErbB-2 signaling in BC (Proietti et al. 2005, 2009). Interestingly, Stat3 plays a key role in mammary cancer (reviewed in Kamran et al. 2013). Nuclear interaction between PR and ErbB-2 was next identified, showing that PR activated by its ligands (the steroid hormones progestins) induces ErbB-2 nuclear translocation and its colocalization and physical association with Stat3 in the nuclear compartment of BC cells. As previously shown for constitutively activated ErbB-2 (Wang et al. 2004), PR induced full-length ErbB-2 protein translocation to the nucleus. Nuclear ErbB-2 was also phosphorylated at tyrosine (Tyr) 1222, a major ErbB-2 autophosphorylation site, as well as at Tyr 877 , a site different from the autophosphorylation ones, located at the kinase domain, in the proximity of the NLS (Guo et al. 2006, Xu et al. 2007). In the nucleus, ErbB-2 assembles a transcriptional complex in which it acts as a coactivator of Stat 3 bound to its response elements (GAS sites) at the promoter of cyclin D1 (Beguelin et al. 2010). Importantly, this region of cyclin D1 proximal promoter lacks HAS sites and canonical PR response elements (PREs), further confirming nuclear ErbB-2's role as coactivator. Notably, PR was also loaded onto the Stat3/ErbB-2 complex. In this newly discovered class of complex, the transcription factor (Stat3) is first phosphorylated at cytoplasmic level via its coactivator (ErbB-2) function as an upstream effector (Beguelin et al. 2010) (Fig. 3 shows a model of ErbB-2/Stat3/PR nuclear interaction consistent with these findings). Interaction of EGF-R and Stat3 at the promoter of the inducible nitric oxide synthase (iNOS), containing both EGF-R-binding sites (AT-rich sequences (ATRSs)) and Stat 3 response elements, was identified in a startling study (Lo et al. 2005). The presence of two clusters of ATRSand Stat3-binding sites was essential for the regulation of the iNOS promoter by EGF-R. This highlights a major difference with respect to the nuclear function of the ErbB-2/Stat3 transcriptional complex in the cyclin D1 promoter, which requires only Stat3 binding to the GAS

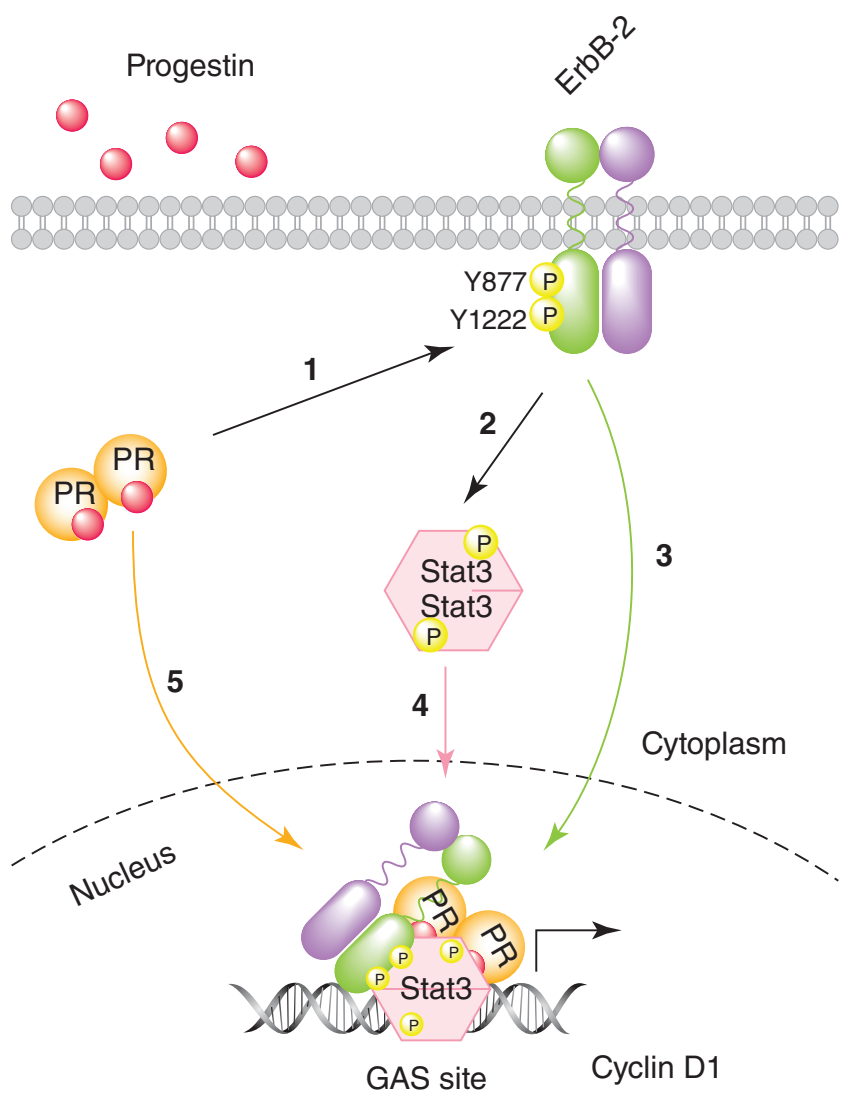

Figure 3

Stat3/ErbB-2/PR transcriptional complex induced by progestins in breast cancer. PR activated by progestins induces the phosphorylation of ErbB-2 at Tyr 1222 and Tyr 877 (1). ErbB-2 activated by a nongenomic PR action stimulates Stat3 phosphorylation (2) (Beguelin et al. 2010). ErbB-2 (3) and Stat3 (4) then translocate to the nucleus where they assemble a transcriptional complex at the Stat3 response element (GAS sites) of the cyclin D1 promoter, in which ErbB-2 acts as a coactivator of Stat3. PR is also loaded on the Stat3/ErbB-2 complex (5).

sites and ErbB-2 recruitment to these sites, where it acts as a Stat 3 coactivator. This discrepancy may indicate that EGF-R/Stat3 and ErbB-2/Stat3 complexes regulate chromatin targets by distinct mechanisms as a general rule. It may also indicate that the nature of the interaction between ErbBs and Stat3 within intact cells depends on the set of Stat3/ErbB-binding motifs available in the target gene promoter/enhancer regions, as well as on the specific sequences and unique structure of the DNA in the vicinity of the Stat3/ErbB-binding sites. Consistent with the latter, Stat3 and EGF-R do not associate at the cyclin D1 promoter, which is regulated by nuclear EGF-R (Lin et al. 2001) and which also contains a cluster of ATRS/ Stat3 sites (Lo et al. 2005).

Nuclear ErbB-2 action in the proliferation of ER-, PR- and ErbB-2-positive BC models was explored by 
transfection of cells with hErbB-2ANLS, a human ErbB-2 nuclear localization domain mutant engineered by Hung and coworkers, unable to translocate to the nucleus and which also functions as a DN inhibitor of endogenous ErbB-2 nuclear migration (Giri et al. 2005, Beguelin et al. 2010). hErbB-2 $\Delta$ NLS retains intrinsic Tyr kinase activity and the capacity to activate ErbB-2 cascades, including p42/p44 MAPKs and Stat3, and it does not affect endogenous ErbB-2 signaling (Wang et al. 2004, Giri et al. 2005, Beguelin et al. 2010). Transfection of BC cells expressing endogenous ErbB-2 with the mutant hErbB-2 $\Delta$ NLS disrupted the assembly of the nuclear Stat3/ErbB-2/PR transcriptional complex at the cyclin D1 promoter, and consequently inhibited growth induced by progestins, both in vitro and in preclinical models (Beguelin et al. 2010). As inhibition of COX-2, a gene induced by ErbB-2 acting as a transcription factor, did not affect the proliferation but inhibited invasion (Wang et al. 2004), further studies are needed either to identify genes regulated by ErbB-2 through its role as a transcription factor, and which may be involved in ErbB-2 proliferative effects, or to define whether the function of ErbB-2 as a transcriptional coactivator may be the one directly involved in ErbB-2-induced stimulation of BC growth. In support of this latter possibility, it was reported that in hormone-dependent $\mathrm{BC}$ cells, progestins induce the expression of cell cycle regulator p21 ${ }^{\mathrm{CIP} 1}$ via phosphorylation of c-Src, Stat3 and ErbB-2 (Diaz Flaque et al. 2013b). Notably, it was also found that ErbB-2 nuclear function plays a key role in progestin induction of p21CIP1 expression (Diaz Flaque et al. 2013b). Progestins were found to induce the assembly of a transcriptional complex where PR is recruited along with Stat 3 and ErbB-2 to a GAS site at the p21 ${ }^{\mathrm{CIP} 1}$ promoter. In this complex, ErbB-2 functions as a coactivator of Stat3 (Diaz Flaque et al. 2013b). The link between nuclear ErbB-2 function as a Stat 3 coactivator and $\mathrm{BC}$ growth was provided by the findings that under progestin stimulation of $\mathrm{BC}$ cells, p21 ${ }^{\mathrm{CIP} 1}$ induces cell cycle progression and that blockage of p21 CIP1 expression strongly inhibited in vitro and in vivo progestin-induced BC proliferation (Diaz Flaque et al. 2013b). Also, providing consistent correlation between ErbB-2's role as a coactivator and its ability to promote BC growth, another study demonstrated that progestins induce the assembly of a transcriptional complex among activator protein 1 (AP-1), Stat3, PR and ErbB-2 at a region of the cyclin D1 promoter containing both AP-1 response elements (TRE) and GAS sites (Diaz Flaque et al. 2013a). This array of transcription factors (AP-1 and Stat3) whose response elements are clustered in the DNA, plus their interacting cofactors (PR and ErbB-2) and coactivators (P300 and CBP), function cooperatively to induce cyclin $\mathrm{D} 1$ promoter activation as well as in vitro and in vivo $\mathrm{BC}$ growth driven by progestins (Diaz Flaque et al. 2013a).

The role of nuclear ErbB-2 in the growth of BC cells overexpressing MErbB-2 was also revealed by a study demonstrating the nuclear colocalization and physical association between ErbB-2, $\beta$-actin and RNA polymerase I (RNA Pol I), which coincide with active RNA Pol I transcription sites in nucleoli (Li et al. 2011). Knockdown of ErbB-2 reduced the synthesis of $45 \mathrm{~S}$ preRNA and of nascent nuclear RNA levels. On the contrary, MCF-7 cells transfected with increasing amounts of wildtype ErbB-2 showed a dose-dependent enhancement of pre-rRNA synthesis (Li et al. 2011). Transfection of cells with the mutant hErbB-2 $\Delta$ NLS resulted in impaired RNA Pol I binding and in significantly lower increase of prerRNA synthesis, highlighting the critical role of nuclear ErbB-2 in the regulation of rRNA transcription (Li et al. 2011). Simultaneous recruitment of ErbB-2, $\beta$-actin and RNA Pol was found at the 5'-terminal region of human rDNA, and at the 28S rRNA transcribed region, in multiple ErbB-2-expressing BC cell lines (Li et al. 2011). Furthermore, association of ErbB-2 with rDNA requires ongoing transcription (Li et al. 2011). Based on the facts that regulation of rRNA transcription by RNA Pol I is a key process for ribosome biogenesis and that the extent of rRNA gene transcription reflects the requirement of protein synthesis associated with the rate of cell growth, the authors of this study analyzed the protein content and biosynthetic rate as a way to explore the function of nuclear ErbB-2. Their findings revealed that nuclear ErbB-2 increases total protein synthesis and cell size, indicating that it may drive $\mathrm{BC}$ growth by enhancing rRNA synthesis and protein translation (Li et al. 2011). Moreover, stimulation of $\mathrm{BC}$ cells with the ErbBs ligand HRG promoted ErbB-2 nuclear translocation and increased $45 \mathrm{~S}$ pre-rRNA levels. Further support of direct nuclear ErbB-2 involvement in the enhancement of RNA pol I transcription was provided by their demonstration that inhibition of MErbB-2-stimulated downstream signaling cascades, such as p42/p44 MAPKs and PI3K-AKT, did not affect HRG-induced 45S pre-rRNA synthesis or HRG enhancement of total protein synthesis (Li et al. 2011).

Interaction of nuclear ErbB-2 with the atypical histone macroH2A1.2 (mH2A1.2) was found in several cancer cell types, including $\mathrm{BC}$, where this interaction participates in the proliferation of cancer cells ( $\mathrm{Li}$ et al. 2012). The study 
of the molecular mechanism underlying ErbB-2/mH2A1.2 crosstalk and its biological effects revealed that ErbB-2 tyrosine kinase activity upregulates mH2A1.2, which in turn stimulates the proliferation and tumorigenicity of ErbB-2-positive BC cells by enhancing ErbB-2 expression at both protein and mRNA levels (Li et al. 2012). Increase of ErbB-2 transcription in mH2A1.2-transfected SKOV-3 ovarian cancer cells was induced by $\mathrm{mH} 2 \mathrm{~A} 1.2$ recruitment to a series of positions at the ErbB-2 proximal promoter encompassing a region up to $5 \mathrm{~kb}$ upstream of the translational start site (Li et al. 2012). It remains to be established whether similar mH2A1.2 occupancy of the ErbB-2 promoter occurs in BC cells, which will highlight ErbB-2's ability to modulate its own transcription as a common mechanism driving cancer growth.

The critical role of both Stat3 and MErbB-2 in BC metastasis has long been demonstrated (reviewed in Freudenberg et al. 2009, Kamran et al. 2013). Furthermore, a series of BC models where transgenic mice carry ErbB-2 under the control of the mouse mammary tumor virus (MMTV) promoter disclosed the involvement of Stat3 as a downstream effector of MErbB-2-induced metastatic dissemination in BC (Muller et al. 1988, Guy et al. 1992, Siegel et al. 1999, Finkle et al. 2004, Ursini-Siegel et al. 2008). Interestingly, a recent study revealed that an unanticipated direction of ErbB-2 and Stat3 interaction, involving nuclear ErbB-2, also plays a key role in BC metastasis (Venturutti et al. 2015). It was reported that Stat3, activated downstream of ErbB-2, binds to its GAS sites at the ErbB-2 promoter, which results in the upregulation of ErbB-2 transcription in metastatic, ErbB-2-positive BC cells (Venturutti et al. 2015). It is highly likely that the fact that Neu/ErbB-2 expression in transgenic mice models was driven by a strong viral promoter previously hampered the study of the TFs and the epigenetic mechanisms controlling endogenous ErbB-2 promoter activation in metastatic BC. ErbB-2 overexpression can occur in the absence of gene amplification, indicating the importance of the dysregulation of the transcriptional control of ErbB-2 expression in BC. Although little is known about the TFs that bind to ErbB-2 promoter/enhancers in BC (Bates \& Hurst 1997, Delacroix et al. 2005, Zuo et al. 2007), the discoveries that ErbB-2 activates mH2A1.2 and Stat3 and recruits them to its promoter, raise the possibility that the general mechanisms by which ErbB-2 modulates its own overexpression in $\mathrm{BC}$ is through the regulation of transcriptional activators, which in turn bind to the ErbB-2 promoter and induce ErbB-2 transcription. The abovementioned study (Venturutti et al. 2015) also reported that as outcome of the feed-forward loop between Stat3 activation and ErbB-2 expression, Stat3 co-opts nuclear ErbB-2 function by recruiting ErbB-2 as its coactivator at the GAS sites in the promoter of microRNA-21 (miR-21), a miRNA whose expression is regulated by MErbB-2, and whose metastasis-promoting effects in BC are well acknowledged (Loffler et al. 2007, Yan et al. 2008, Huang et al. 2009, Iliopoulos et al. 2010, Song et al. 2010, Yang et al. 2011, Han et al. 2012, Niu et al. 2012, Marino et al. 2014). By means of the hErbB-2 $\Delta$ NLS nuclear localization domain mutant and a constitutively activated ErbB-2 variant, it was shown that nuclear ErbB-2, in its role as a Stat3 coactivator at the miR-21 promoter, and also, notably, in its direct role as a transcription factor bound to its HAS sites, upregulates miR-21 in metastatic BC (Venturutti et al. 2015). This was the first demonstration that nuclear ErbB-2 regulates a microRNA in any normal or malignant cell type. Increased levels of miR-21, in turn, downregulate the expression of the metastasis-suppressor protein programmed cell death 4 (PDCD4), a validated miR-21 target (Zhu et al. 2008, Huang et al. 2009, NievesAlicea et al. 2009). Using an in vivo model of metastatic ErbB-2-positive BC, in which Stat3 was silenced and the expressions of ErbB-2 or of miR-21 were reconstituted, it was shown that both are downstream mediators of Stat3driven metastasis (Venturutti et al. 2015). Furthermore, an inverse correlation between ErbB-2/Stat3 nuclear coexpression and PDCD4 expression was found in ErbB2-positive primary invasive BCs (Venturutti et al. 2015). These findings, consistent with the previous study where inactivation of COX-2, a direct transcriptional target of nuclear ErbB-2, hampered migration of ErbB-2-positive BC cells (Wang et al. 2004) strongly support nuclear ErbB-2's role in $\mathrm{BC}$ metastasis.

\section{Nuclear ErbB-2's role in the response to $\mathrm{BC}$ therapies}

Full-length ErbB-2 located in the nuclear compartment was found to participate in the mechanisms of $\mathrm{BC}$ resistance to chemotherapeutic agents and to anti-MErbB-2 therapies.

\section{Chemotherapy}

ErbB-2 phosphorylates the cyclin-dependent kinase Cdc2 at tyrosine 15 (Tyr15) in BC cells, which leads to the inhibition of Cdc2 activation (Tan et al. 2002). This inhibitory phosphorylation of Cdc2 by ErbB-2 participates in taxol resistance (Tan et al. 2002). Notably, 
it was also found that in the nuclear compartment of ErbB-2-overexpressing BC cells, ErbB-2 colocalizes with the Cdc2/cyclin B complexes, raising the exciting possibility that nuclear ErbB-2 may contribute to the inhibition of Cdc2 activation and thus to resistance to taxol (Tan et al. 2002). Another study demonstrated that lapatinib, a dual tyrosine kinase inhibitor of EGF-R and ErbB-2 (Medina \& Goodin 2008), sensitizes ErbB-2-amplified gastric cells to the antiproliferative effects of the chemotherapeutic agents fluoropyrimidines, such as $5 \mathrm{FU}$, which inhibit thymidylate synthase (TS) activity (Kim et al. 2008, 2009). Lapatinib treatment of said cells was found to reduce TS expression at protein and mRNA levels (Kim et al. 2009). The study of the molecular mechanism underlying lapatinib effects demonstrated that EGF induced the nuclear translocation of EGF-R and ErbB-2, where both bind to the TS promoter (Kim et al. 2009). Lapatinib prevented EGF-R and ErbB-2 nuclear migration and thus their recruitment to the TS promoter, which ultimately results in TS downregulation (Kim et al. 2009). Interestingly, lapatinib also blocks EGF-induced recruitment of EGF-R and ErbB-2 to the TS promoter in ErbB-2-overexpressing SKBR3 BC cells (Kim et al. 2009). The study provided no description of the response element to which EGF-R or ErbB-2 binds at the TS promoter (Kim et al. 2009).

\section{Anti-MErbB-2 therapies}

Recently, basal nuclear ErbB-2, ErbB-3 and Stat3, as well as ErbB-2/ErbB-3 and ErbB-2/Stat3 nuclear colocalization were detected in multiple TZ-responsive and -resistant ErbB-2-positive human BC lines (Cordo Russo et al. 2015). HRG $\beta 1$ increased nuclear migration and colocalization of all three proteins. Basal MErbB-2/MErbB-3 dimers were more numerous in TZ-sensitive cells than in -resistant cells, whereas, conversely, nuclear dimers were more abundant in resistant cells, highlighting a role of nuclear ErbB dimers in TZ response (Cordo Russo et al. 2015). Basal and HRG $\beta 1$-induced assembly of a Stat $3 /$ ErbB-2/ErbB-3 transcriptional complex at the GAS sites of the cyclin D1 promoter was found in both cell types, where ErbB-2 and ErbB-3 act as Stat3 cofactors (Cordo Russo et al. 2015). This was the first report of a nuclear function of the ErbB-2/ErbB-3 dimer, resulting in the regulation of cyclin D1 expression. Inhibition of ErbB-2 nuclear localization by transfer of hErbB-2 $\Delta$ NLS blocked basal and HRG $\beta 1$-stimulated in vitro growth of ErbB-2amplified human BC cells, both TZ sensitive and resistant, as well as the proliferation of a preclinical model of
TZ-resistant BC in the presence of ErbB-2/ErbB-3 dimers, of ErbB-3 phosphorylation and of PI3K/AKT pathway activation (Cordo Russo et al. 2015), conditions where TZ is inefficient (Yakes et al. 2002, Nagata et al. 2004, Junttila et al. 2009, Ghosh et al. 2011). Disruption of the Stat3/ErbB-2/ErbB-3 nuclear complex driving cyclin D1 expression was identified as the differential molecular signature underlying hErbB-2 $\Delta$ NLS's growth inhibitory effects in TZ-resistant cells (Cordo Russo et al. 2015). These series of findings support a model (Fig. 4) where, in cells displaying higher levels of MErbB-2 than of nuclear ErbB-2, proliferation is driven by signaling and by nuclear ErbB-2 actions, both hierarchically equal. Inhibition of signaling with TZ or of nuclear actions with hErbB-2 $\Delta$ NLS would therefore block proliferation. On the contrary, nuclear ErbB-2's role on proliferation is stronger than that of MErbB-2 in BC cells displaying higher levels of nuclear ErbB-2. Thus, only inhibition of nuclear ErbB-2 effects would inhibit proliferation (Fig. 4).

\section{Truncated nuclear ErbB-2 variants in the response to $B C$ therapies}

The biological and clinical significance of the presence of truncated ErbB-2 forms in the nucleus of BC cells still remains to be unequivocally established. It has been demonstrated that transfection of $\mathrm{BC}$ cells, including T47D and MCF-7 cells displaying low-to-moderate MErbB-2 levels, and of MDA-MB-468 cells, which lack MErbB-2 expression, with p95ErbB-2 variants, results in cytoplasmic and nuclear presence of these truncated ErbB-2 forms (Anido et al. 2006, Scaltriti et al. 2007). Also, p95ErbB-2 variants have been found in primary breast tumors (Scaltriti et al. 2007). As reported for the fulllength ErbB-2 (Wang et al. 2004, Cordo Russo et al. 2015), tyrosine kinase activity of p95ErbB-2 variants appears to be required for their nuclear translocation (Anido et al. 2006). The role of nuclear p95ErbB-2 variants in the response to anti-MErbB-2 therapies remains poorly explored. Lapatinib was found to increase the expression of a tyrosine phosphorylated p95ErbB-2 form (p95L) in MErbB-2-positive BC cells, which was located in the nuclear compartment (Xia et al. 2004). The generation of p95L appears to be mediated by the proteosome. Tyrosine phosphorylation of $\mathrm{p} 95 \mathrm{~L}$ was not inhibited by either lapatinib or GW2974, another tyrosine kinase inhibitor (Xia et al. 2004). Furthermore, enhanced expression of p95L was detected in BC cells and in tumor xenografts resistant to lapatinib, and metastasis 


\section{Trastuzumab-sensitive cells}

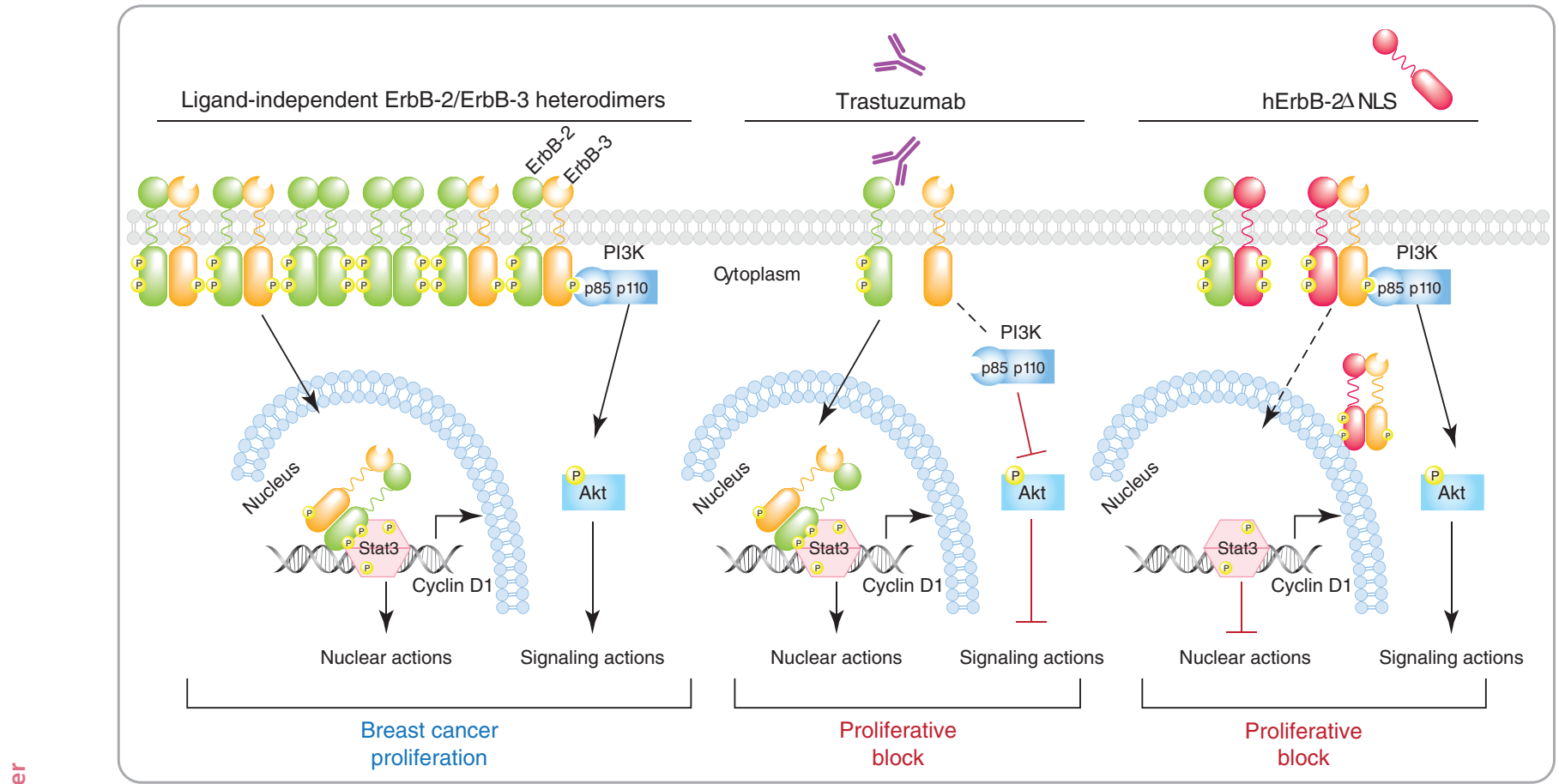

Trastuzumab-resistant cells

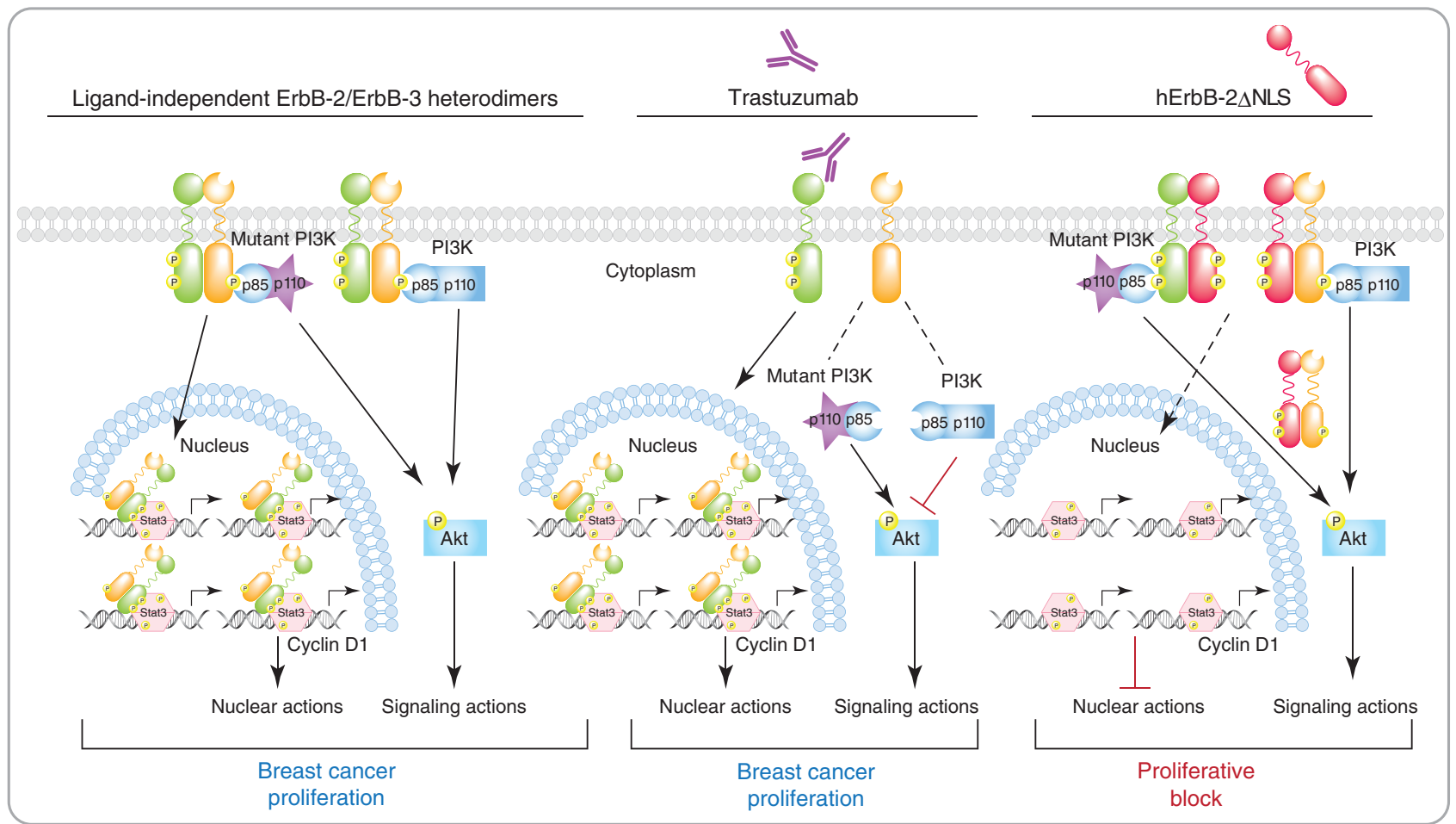

Figure 4

Nuclear ErbB-2's role in the response to trastuzumab (TZ). BC cells sensitive to TZ show higher levels of MErbB-2 than those of NErbB-2. Their proliferation is stimulated by ErbB-2 signaling (e.g. PI3K/AKT) and nuclear (e.g. Stat3/ErbB-2/ErbB-3 transcriptional complex at cyclin D1 promoter) actions, both hierarchically equal. Inhibition of signaling with TZ or of nuclear action with hErbB-2 $\triangle$ NLS inhibits proliferation. TZ-resistant cells show high levels of NErbB-2, which may be higher than those of MErbB-2. Nuclear ErbB-2 effect on proliferation is stronger than that of MErbB-2. Blockade of nuclear ErbB-2 effect with hErbB-2 $\triangle \mathrm{NLS}$ prevents $\mathrm{BC}$ growth in spite of the activation of signaling cascades. 
developed while patients were treated with lapatinib (Xia et al. 2004). Also, when tyrosine-phosphorylated p95ErbB-2 variants, generated by alternate initiation of translation, were expressed in BC cells, they localized at the nucleus and rendered $\mathrm{BC}$ cells resistant to lapatinib (Xia et al. 2004). These results point to a role of nuclear ErbB-2 CTFs in acquired resistance to lapatinib. However, the above findings still have to be reconciled with a series of other studies, which show that lapatinib antiproliferative effects in $\mathrm{BC}$ are, indeed, mediated by lapatinib's ability to prevent MErbB-2 phosphorylation and nuclear migration, and to block its ubiquitination, which results in a marked accumulation of inactive ErbB-2, ErbB-2 homodimers, and ErbB-2/ErbB-3 heterodimers at cell surface (Kim et al. 2009, Scaltriti et al. 2009, Vazquez-Martin et al. 2011). Also, it has been reported that along with lapatinib's ability to increase the concentration of the unphosphorylated form of ErbB-2 in the membrane of $\mathrm{BC}$ cells, lapatinib increases the basal shedding of ErbB-2 ECD to inhibit BC cell growth (Vazquez-Martin et al. 2011). Previous findings showed that transfection into BC cells of 611-CTF induces a significant downregulation of ER and causes resistance to antiestrogen therapy (Parra-Palau et al. 2010). Since, as described previously, it was shown that truncated ErbB-2 variants localize in the nuclear compartment when introduced into BC cells (Anido et al. 2006, Scaltriti et al. 2007), it is tempting to speculate that the nuclear function of 611-CTF may also be involved in endocrine therapy resistance.

\section{Clinical significance of nuclear ErbB-2 as a biomarker in BC}

To the best of our knowledge, there are only few works that have explored in the clinic the role of full-length nuclear ErbB-2 as a biomarker of the course of the disease and as a predictor of response to therapy. In a cohort of primary breast tumors, an inverse correlation was reported between ER expression and expressions of nuclear ErbB-2 and Cox-2 (Dillon et al. 2008), a gene that, as described previously, is a direct transcriptional target of nuclear ErbB-2 (Wang et al. 2004). Nuclear ErbB-2's presence was associated with tumor size and grade. In this study, both nuclear ErbB-2 and COX-2 were associated with reduced disease-free survival in patients receiving tamoxifen in the adjuvant setting (Dillon et al. 2008). More recent clinical studies in a small cohort of primary invasive BCs revealed a role for nuclear ErbB-2 as an independent prognostic factor of poor clinical outcome in MErbB-2-positive tumors (Schillaci et al. 2012).

\section{Conclusions}

Compelling evidence has shown ErbB-2's localization at the nucleus of ErbB-2-positive BC cells, where it regulates multiple biological responses. Nuclear ErbB-2 participates in key features of $\mathrm{BC}$, which turn this disease extremely difficult to defeat. Nuclear ErbB-2 is involved in BC proliferation, as well as in BC's ability to metastasize at distant organs. Lastly, it is also involved in BC's de novo resistance to systemic therapies and in BC's ability to develop compensatory growth mechanisms leading to acquired resistance to therapy. All these findings notwithstanding, and in spite of the increasing knowledge on the mechanism of ErbB-2 nuclear trafficking, the clinical significance of nuclear ErbB-2 in BC still remains to be established. Furthermore, for reasons that remain unclear, there is no single drug designed to target nuclear ErbB-2 function. Intriguingly, genome-wide studies to explore the genomic function of ErbB-2 in MErbB-2-overexpressing $\mathrm{BC}$ cells, or in any other cell type, have not yet been done. The specific gene signature resulting from the ErbB-2 cistrome might serve as a novel biomarker of clinical outcome. In addition, genes unraveled through a genomewide approach might constitute novel targets of therapy. A most interesting question that also needs to be addressed is whether ErbB-2 exerts its tyrosine kinase activity also in the nuclear compartment. We hope that the findings here reviewed provide enough food for thought and help us wonder whether targeting nuclear ErbB-2 could be a mighty weapon to fight ErbB-2-positive BC.

Declaration of interest

The authors declare that there is no conflict of interest that could be perceived as prejudicing the impartiality of this review.

\section{Funding}

This work was supported by IDB/PICT 2012-668 and PID 2012-066 from the National Agency of Scientific Promotion of Argentina (ANPCyT) and by a grant from the Nelia and Amadeo Barletta Foundation from Switzerland, awarded to P V E.

\section{Acknowledgements}

The authors thank Mien-Chie Hung (MD Anderson Cancer Center, Houston, TX, USA) for his generous help and support during the course of our studies of ErbB-2 nuclear function. 


\section{References}

Abe Y, Matsumoto S, Wei S, Nezu K, Miyoshi A, Kito K, Ueda N, Shigemoto K, Hitsumoto Y, Nikawa J, et al. 2001 Cloning and characterization of a P53-related protein kinase expressed in interleukin-2-activated cytotoxic T-cells, epithelial tumor cell lines, and the testes. Journal of Biological Chemistry 276 44003-44011. (doi:10.1074/jbc.M105669200)

Anido J, Scaltriti M, Bech Serra JJ, Santiago JB, Todo FR, Baselga J \& Arribas J 2006 Biosynthesis of tumorigenic HER2 C-terminal fragments by alternative initiation of translation. EMBO Journal $\mathbf{2 5}$ 3234-3244. (doi:10.1038/sj.emboj.7601191)

Balana ME, Lupu R, Labriola L, Charreau EH \& Elizalde PV 1999 Interactions between progestins and heregulin (HRG) signaling pathways: HRG acts as mediator of progestins proliferative effects in mouse mammary adenocarcinomas. Oncogene 18 6370-6379. (doi:10.1038/sj.onc.1203028)

Barbieri I, Pensa S, Pannellini T, Quaglino E, Maritano D, Demaria M, Voster A, Turkson J, Cavallo F, Watson CJ, et al. 2010a Constitutively active Stat3 enhances Neu-mediated migration and metastasis in mammary tumors via upregulation of Cten. Cancer Research 70 2558-2567. (doi:10.1158/0008-5472.CAN-09-2840)

Barbieri I, Quaglino E, Maritano D, Pannellini T, Riera L, Cavallo F, Forni G, Musiani P, Chiarle R \& Poli V 2010b Stat3 is required for anchorage-independent growth and metastasis but not for mammary tumor development downstream of the ErbB-2 oncogene. Molecular Carcinogenesis 49 114-120. (doi:10.1002/mc.20605)

Bargmann CI, Hung MC \& Weinberg RA 1986 The Neu oncogene encodes an epidermal growth factor receptor-related protein. Nature 319 226-230. (doi:10.1038/319226a0)

Bates NP \& Hurst HC 1997 An intron 1 enhancer element mediates oestrogen-induced suppression of ERBB2 expression. Oncogene 15 473-481. (doi:10.1038/sj.onc.1201368)

Beguelin W, Diaz Flaque MC, Proietti CJ, Cayrol F, Rivas MA, Tkach M, Rosemblit C, Tocci JM, Charreau EH, Schillaci R, et al. 2010 Progesterone receptor induces ErbB-2 nuclear translocation to promote breast cancer growth via a novel transcriptional effect: ErbB-2 function as a coactivator of Stat3. Molecular and Cellular Biology 30 5456-5472. (doi:10.1128/MCB.00012-10)

Bertelsen V \& Stang E 2014 The mysterious ways of ErbB2/HER2 trafficking. Membranes 4 424-446. (doi:10.3390/membranes4030424)

Bonifacino JS \& Rojas R 2006 Retrograde Transport from endosomes to the trans-golgi network. Nature Reviews Molecular Cell Biology 7 568-579. (doi:10.1038/nrm1985)

Brand TM, Iida M, Luthar N, Wleklinski MJ, Starr MM \& Wheeler DL 2013 Mapping C-terminal transactivation domains of the nuclear HER family receptor tyrosine kinase HER3. PLOS ONE 8 e71518. (doi:10.1371/journal.pone.0071518)

Burgess AW 2008 EGFR family: structure physiology signalling and therapeutic targets. Growth Factors 26 263-274. (doi:10.1080/08977190802312844)

Carpenter G \& Liao HJ 2013 Receptor tyrosine kinases in the nucleus. Cold Spring Harbor Perspectives in Biology 5 a008979.

Chen MK \& Hung MC 2015 Proteolytic cleavage, trafficking, and functions of nuclear receptor tyrosine kinases. FEBS Journal $\mathbf{2 8 2}$ 3693-3721. (doi:10.1111/febs.13342)

Chen QQ, Chen XY, Jiang YY \& Liu J 2005 Identification of novel nuclear localization signal within the ErbB-2 protein. Cell Research 15 504-510. (doi:10.1038/sj.cr.7290320)

Cho HS, Mason K, Ramyar KX, Stanley AM, Gabelli SB, Denney DW Jr \& Leahy DJ 2003 Structure of the extracellular region of HER2 alone and in complex with the herceptin fab. Nature 421 756-760. (doi:10.1038/nature01392)

Codony-Servat J, Albanell J, Lopez-Talavera JC, Arribas J \& Baselga J 1999 Cleavage of the HER2 ectodomain is a pervanadate-activable process that is inhibited by the tissue inhibitor of metalloproteases- 1 in breast cancer cells. Cancer Research 59 1196-1201.

Cordo Russo RI, Beguelin W, Diaz Flaque MC, Proietti C, Venturutti L, Galigniana NM, Tkach M, Guzman P, Roa JC, O'Brien N, et al. 2015 Targeting ErbB-2 nuclear localization and function inhibits breast cancer growth and overcomes trastuzumab resistance. Oncogene $\mathbf{3 4}$ 3413-3428. (doi:10.1038/onc.2014.272)

Delacroix L, Begon D, Chatel G, Jackers P \& Winkler R 2005 Distal ERBB2 promoter fragment displays specific transcriptional and nuclear binding activities in ERBB2 overexpressing breast cancer cells. DNA and Cell Biology 24 582-594. (doi:10.1089/ dna.2005.24.582)

Diaz Flaque MC, Galigniana NM, Beguelin W, Vicario R, Proietti CJ, Russo RC, Rivas MA, Tkach M, Guzman P, Roa JC, et al. $2013 a$ Progesterone receptor assembly of a transcriptional complex along with activator protein 1 , signal transducer and activator of transcription 3 and ErbB-2 governs breast cancer growth and predicts response to endocrine therapy. Breast Cancer Research $\mathbf{1 5}$ R118. (doi:10.1186/bcr3587)

Diaz Flaque MC, Vicario R, Proietti CJ, Izzo F, Schillaci R \& Elizalde PV $2013 b$ Progestin drives breast cancer growth by inducing P21(CIP1) expression through the assembly of a transcriptional complex among Stat3, progesterone receptor and ErbB-2. Steroids 78 559-567. (doi:10.1016/j.steroids.2012.11.003)

Dillon MF, Stafford AT, Kelly G, Redmond AM, McIlroy M, Crotty TB, McDermott E, Hill AD \& Young LS 2008 Cyclooxygenase-2 predicts adverse effects of tamoxifen: a possible mechanism of role for nuclear HER2 in breast cancer patients. Endocrine-Related Cancer 15 745-753. (doi:10.1677/ERC-08-0009)

Esteva FJ, Valero V, Booser D, Guerra LT, Murray JL, Pusztai L, Cristofanilli M, Arun B, Esmaeli B, Fritsche HA, et al. 2002 Phase II study of weekly docetaxel and trastuzumab for patients with HER-2overexpressing metastatic breast cancer. Journal of Clinical Oncology 20 1800-1808. (doi:10.1200/JCO.2002.07.058)

Esteva FJ, Yu D, Hung MC \& Hortobagyi GN 2010 Molecular predictors of response to trastuzumab and lapatinib in breast cancer. Nature Reviews Clinical Oncology 7 98-107. (doi:10.1038/nrclinonc.2009.216)

Finkle D, Quan ZR, Asghari V, Kloss J, Ghaboosi N, Mai E, Wong WL, Hollingshead P, Schwall R, Koeppen H, et al. 2004 HER2-targeted therapy reduces incidence and progression of midlife mammary tumors in female murine mammary tumor virus HuHER2-transgenic mice. Clinical Cancer Research 10 2499-2511. (doi:10.1158/10780432.CCR-03-0448)

Freudenberg JA, Wang Q, Katsumata M, Drebin J, Nagatomo I \& Greene MI 2009 The role of HER2 in early breast cancer metastasis and the origins of resistance to HER2-targeted therapies. Experimental and Molecular Pathology 87 1-11. (doi:10.1016/j.yexmp.2009.05.001)

Garcia-Castillo J, Pedersen K, Angelini PD, Bech-Serra JJ, Colome N, Cunningham MP, Parra-Palau JL, Canals F, Baselga J \& Arribas J 2009 HER2 carboxyl-terminal fragments regulate cell migration and cortactin phosphorylation. Journal of Biological Chemistry $\mathbf{2 8 4}$ 25302-25313. (doi:10.1074/jbc.M109.001982)

Garrett JT, Olivares MG, Rinehart C, Granja-Ingram ND, Sanchez V, Chakrabarty A, Dave B, Cook RS, Pao W, McKinely E, et al. 2011 Transcriptional and posttranslational up-regulation of HER3 (ErbB3) compensates for inhibition of the HER2 tyrosine kinase. PNAS 108 5021-5026. (doi:10.1073/pnas.1016140108)

Garrett TP, McKern NM, Lou M, Elleman TC, Adams TE, Lovrecz GO, Kofler M, Jorissen RN, Nice EC, Burgess AW, et al. 2003 The crystal structure of a truncated ErbB2 ectodomain reveals an active conformation, poised to interact with other ErbB receptors. Molecular Cell 11 495-505. (doi:10.1016/S1097-2765(03)00048-0)

Geyer CE, Forster J, Lindquist D, Chan S, Romieu CG, Pienkowski T, Jagiello-Gruszfeld A, Crown J, Chan A, Kaufman B, et al. 2006 Lapatinib plus capecitabine for HER2-positive advanced breast
(C) 2016 Society for Endocrinology Printed in Great Britain
Published by Bioscientifica Ltd 
cancer. New England Journal of Medicine 355 2733-2743. (doi:10.1056/NEJMoa064320)

Ghosh R, Narasanna A, Wang SE, Liu S, Chakrabarty A, Balko JM, Gonzalez-Angulo AM, Mills GB, Penuel E, Winslow J, et al. 2011 Trastuzumab has preferential activity against breast cancers driven by HER2 homodimers. Cancer Research 71 1871-1882. (doi:10.1158/0008-5472.CAN-10-1872)

Giri DK, Ali-Seyed M, Li LY, Lee DF, Ling P, Bartholomeusz G, Wang SC \& Hung MC 2005 Endosomal transport of ErbB-2: mechanism for nuclear entry of the cell surface receptor. Molecular and Cellular Biology 25 11005-11018. (doi:10.1128/MCB.25.24.11005-11018.2005)

Graus-Porta D, Beerli RR, Daly JM \& Hynes NE 1997 ErbB-2, the preferred heterodimerization partner of all ErbB receptors, is a mediator of lateral signaling. EMBO Journal 16 1647-1655. (doi:10.1093/emboj/16.7.1647)

Guo W, Pylayeva Y, Pepe A, Yoshioka T, Muller WJ, Inghirami G \& Giancotti FG 2006 Beta 4 integrin amplifies ErbB2 signaling to promote mammary tumorigenesis. Cell 126 489-502. (doi:10.1016/j. cell.2006.05.047)

Gusterson B, Cowley G, Smith JA \& Ozanne B 1984 Cellular localisation of human epidermal growth factor receptor. Cell Biology International Reports 8 649-658. (doi:10.1016/0309-1651(84)90045-6)

Guy CT, Webster MA, Schaller M, Parsons TJ, Cardiff RD \& Muller WJ 1992 Expression of the Neu protooncogene in the mammary epithelium of transgenic mice induces metastatic disease. PNAS 89 10578-10582. (doi:10.1073/pnas.89.22.10578)

Han M, Liu M, Wang Y, Mo Z, Bi X, Liu Z, Fan Y, Chen X \& Wu C 2012 Re-expression of MiR-21 contributes to migration and invasion by inducing epithelial-mesenchymal transition consistent with cancer stem cell characteristics in MCF-7 cells. Molecular and Cellular Biochemistry 363 427-436. (doi:10.1007/s11010-011-1195-5)

Henderson IC \& Patek AJ 1998 The relationship between prognostic and predictive factors in the management of breast cancer. Breast Cancer Research and Treatment 52 261-288. (doi:10.1023/A:1006141703224)

Hsu SC \& Hung MC 2007 Characterization of a novel tripartite nuclear localization sequence in the EGFR family. Journal of Biological Chemistry 282 10432-10440. (doi:10.1074/jbc.M610014200)

Huang TH, Wu F, Loeb GB, Hsu R, Heidersbach A, Brincat A, Horiuchi D, Lebbink RJ, Mo YY, Goga A, et al. 2009 Up-regulation of MiR-21 by HER2/Neu signaling promotes cell invasion. Journal of Biological Chemistry 284 18515-18524. (doi:10.1074/jbc. M109.006676)

Iliopoulos D, Jaeger SA, Hirsch HA, Bulyk ML \& Struhl K 2010 STAT3 activation of MiR-21 and MiR-181b-1 via PTEN and CYLD are part of the epigenetic switch linking inflammation to cancer. Molecular Cell 39 493-506. (doi:10.1016/j.molcel.2010.07.023)

Ishizawar R \& Parsons SJ 2004 C-Src and cooperating partners in human cancer. Cancer Cell 6 209-214. (doi:10.1016/j.ccr.2004.09.001)

Junttila TT, Akita RW, Parsons K, Fields C, Lewis Phillips GD, Friedman LS, Sampath D \& Sliwkowski MX 2009 Ligandindependent HER2/HER3/PI3K complex is disrupted by trastuzumab and is effectively inhibited by the PI3K inhibitor GDC-0941. Cancer Cell 15 429-440. (doi:10.1016/j.ccr.2009.03.020)

Jura N, Shan Y, Cao X, Shaw DE \& Kuriyan J 2009 Structural analysis of the catalytically inactive kinase domain of the human EGF receptor 3. PNAS 106 21608-21613. (doi:10.1073/pnas.0912101106)

Kamran MZ, Patil P \& Gude RP 2013 Role of STAT3 in cancer metastasis and translational advances. BioMed Research International 2013 421821. (doi:10.1155/2013/421821)

Kim HP, Yoon YK, Kim JW, Han SW, Hur HS, Park J, Lee JH, Oh DY, Im SA, Bang YJ, et al. 2009 Lapatinib, a dual EGFR and HER2 tyrosine kinase inhibitor, downregulates thymidylate synthase by inhibiting the nuclear translocation of EGFR and HER2. PLOS ONE 4 e5933. (doi:10.1371/journal.pone.0005933)

Kim JW, Kim HP, Im SA, Kang S, Hur HS, Yoon YK, Oh DY, Kim JH, Lee DS, Kim TY, et al. 2008 The growth inhibitory effect of lapatinib, a dual inhibitor of EGFR and HER2 tyrosine kinase, in gastric cancer cell lines. Cancer Letters 272 296-306. (doi:10.1016/j. canlet.2008.07.018)

Labriola L, Salatino M, Proietti CJ, Pecci A, Coso OA, Kornblihtt AR, Charreau EH \& Elizalde PV 2003 Heregulin induces transcriptional activation of the progesterone receptor by a mechanism that requires functional ErbB-2 and mitogen-activated protein kinase activation in breast cancer cells. Molecular and Cellular Biology 23 1095-1111. (doi:10.1128/MCB.23.3.1095-1111.2003)

Landgraf R 2007 HER2 therapy. HER2 (ERBB2): functional diversity from structurally conserved building blocks. Breast Cancer Research 9202. (doi:10.1186/bcr1633)

Lee HH, Wang YN \& Hung MC 2015 Non-canonical signaling mode of the epidermal growth factor receptor family. American Journal of Cancer Research 5 2944-2958.

Li LY, Chen H, Hsieh YH, Wang YN, Chu HJ, Chen YH, Chen HY, Chien PJ, Ma H T, Tsai HC, et al. 2011 Nuclear ErbB2 enhances translation and cell growth by activating transcription of ribosomal RNA genes. Cancer Research 71 4269-4279. (doi:10.1158/0008-5472. CAN-10-3504)

Li X, Kuang J, Shen Y, Majer MM, Nelson CC, Parsawar K, Heichman KA \& Kuwada SK 2012 The atypical histone macroH2A1.2 interacts with HER-2 protein in cancer cells. Journal of Biological Chemistry $\mathbf{2 8 7}$ 23171-23183. (doi:10.1074/jbc.M112.379412)

Lin SY, Makino K, Xia W, Matin A, Wen Y, Kwong KY, Bourguignon L \& Hung MC 2001 Nuclear localization of EGF receptor and its potential new role as a transcription factor. Nature Cell Biology $\mathbf{3}$ 802-808. (doi:10.1038/ncb0901-802)

Lin YZ \& Clinton GM 1991 A soluble protein related to the HER-2 proto-oncogene product is released from human breast carcinoma cells. Oncogene 6 639-643.

Liu PC, Liu X, Li Y, Covington M, Wynn R, Huber R, Hillman M, Yang G, Ellis D, Marando C, et al. 2006 Identification of ADAM10 as a major source of HER2 ectodomain sheddase activity in HER2 overexpressing breast cancer cells. Cancer Biology and Therapy $\mathbf{5}$ 657-664. (doi:10.4161/cbt.5.6.2708)

Lo HW, Hsu SC, Ali-Seyed M, Gunduz M, Xia W, Wei Y, Bartholomeusz G, Shih JY \& Hung MC 2005 Nuclear interaction of EGFR and STAT3 in the activation of the INOS/NO pathway. Cancer Cell 7 575-589. (doi:10.1016/j.ccr.2005.05.007)

Loffler D, Brocke-Heidrich K, Pfeifer G, Stocsits C, Hackermuller J, Kretzschmar AK, Burger R, Gramatzki M, Blumert C, Bauer K, et al. 2007 Interleukin-6 dependent survival of multiple myeloma cells involves the Stat3-mediated induction of microRNA-21 through a highly conserved enhancer. Blood 110 1330-1333. (doi:10.1182/ blood-2007-03-081133)

Marino AL, Evangelista AF, Vieira RA, Macedo T, Kerr LM, AbrahaoMachado LF, Longatto-Filho A, Silveira HC \& Marques MM 2014 MicroRNA expression as risk biomarker of breast cancer metastasis: a pilot retrospective case-cohort study. BMC Cancer 14739. (doi:10.1186/1471-2407-14-739)

Maxmen A 2012 The hard facts. Nature 485 S50-S51. (doi:10.1038/485S50a)

Mayer IA \& Arteaga CL 2016 The PI3K/AKT pathway as a target for cancer treatment. Annual Review of Medicine 67 11-28. (doi:10.1146/ annurev-med-062913-051343)

Medina PJ \& Goodin S 2008 Lapatinib: a dual inhibitor of human epidermal growth factor receptor tyrosine kinases. Clinical Therapeutics 30 1426-1447. (doi:10.1016/j.clinthera.2008.08.008)

Molina MA, Saez R, Ramsey EE, Garcia-Barchino MJ, Rojo F, Evans AJ, Albanell J, Keenan EJ, Lluch A, Garcia-Conde J, et al. 2002 NH(2)terminal truncated HER-2 protein but not full-length receptor is associated with nodal metastasis in human breast cancer. Clinical Cancer Research 8 347-353.

Muller WJ, Sinn E, Pattengale PK, Wallace R \& Leder P 1988 Single-step induction of mammary adenocarcinoma in transgenic mice bearing

Published by Bioscientifica Ltd. 
the activated C-Neu oncogene. Cell 54 105-115. (doi:10.1016/00928674(88)90184-5)

Nagata Y, Lan KH, Zhou X, Tan M, Esteva FJ, Sahin AA, Klos KS, Li P, Monia BP, Nguyen NT, et al. 2004 PTEN activation contributes to tumor inhibition by trastuzumab, and loss of PTEN predicts trastuzumab resistance in patients. Cancer Cell 6 117-127. (doi:10.1016/j.ccr.2004.06.022)

Ni CY, Murphy MP, Golde TE \& Carpenter G 2001 Gamma-secretase cleavage and nuclear localization of ErbB-4 receptor tyrosine kinase. Science 294 2179-2181. (doi:10.1126/science.1065412)

Nieves-Alicea R, Colburn NH, Simeone AM \& Tari AM 2009 Programmed cell death 4 inhibits breast cancer cell invasion by increasing tissue inhibitor of metalloproteinases-2 expression. Breast Cancer Research and Treatment 114 203-209. (doi:10.1007/s10549-008-9993-5)

Niu J, Shi Y, Tan G, Yang CH, Fan M, Pfeffer LM \& Wu ZH 2012 DNA damage induces NF-kappaB-dependent microRNA-21 up-regulation and promotes breast cancer cell invasion. Journal of Biological Chemistry 287 21783-21795. (doi:10.1074/jbc.M112.355495)

Offterdinger M, Schofer C, Weipoltshammer K \& Grunt TW 2002 C-ErbB-3: a nuclear protein in mammary epithelial cells. Journal of Cell Biology 157 929-939. (doi:10.1083/jcb.200109033)

Olayioye MA, Neve RM, Lane HA \& Hynes NE 2000 The ErbB signaling network: receptor heterodimerization in development and cancer. EMBO Journal 19 3159-3167. (doi:10.1093/emboj/19.13.3159)

Parra-Palau JL, Pedersen K, Peg V, Scaltriti M, Angelini PD, Escorihuela M, Mancilla S, Sanchez PA, Ramon YC, Baselga J, et al. 2010 A major role of P95/611-CTF, a carboxy-terminal fragment of HER2, in the down-modulation of the estrogen receptor in HER2positive breast cancers. Cancer Research 70 8537-8546. (doi:10.1158/0008-5472.CAN-10-1701)

Patel TA, Dade B, Rodriguez AA, Chang JC, Perez E \& Colon-Otero G 2014 Dual HER2 blockade: preclinical and clinical data. Breast Cancer Research 16 419. (doi:10.1186/s13058-014-0419-5)

Pedersen K, Angelini PD, Laos S, Bach-Faig A, Cunningham MP, FerrerRamon C, Luque-Garcia A, Garcia-Castillo J, Parra-Palau JL, Scaltriti M, et al. 2009 A naturally occurring HER2 carboxy-terminal fragment promotes mammary tumor growth and metastasis. Molecular and Cellular Biology 29 3319-3331. (doi:10.1128/ MCB.01803-08)

Popescu NC, King CR \& Kraus MH 1989 Localization of the human ErbB-2 gene on normal and rearranged chromosomes 17 to bands Q12-21.32. Genomics 4 362-366. (doi:10.1016/08887543(89)90343-1)

Proietti C, Salatino M, Rosemblit C, Carnevale R, Pecci A, Kornblihtt AR, Molinolo AA, Frahm I, Charreau EH, Schillaci R, et al. 2005 Progestins induce transcriptional activation of signal transducer and activator of transcription 3 (Stat3) via a Jak- and Src-dependent mechanism in breast cancer cells. Molecular and Cellular Biology 25 4826-4840. (doi:10.1128/MCB.25.12.4826-4840.2005)

Proietti CJ, Rosemblit C, Beguelin W, Rivas MA, Diaz Flaque MC, Charreau EH, Schillaci R \& Elizalde PV 2009 Activation of Stat3 by heregulin/ErbB-2 through the co-option of progesterone receptor signaling drives breast cancer growth. Molecular and Cellular Biology 29 1249-1265. (doi:10.1128/MCB.00853-08)

Pupa SM, Menard S, Morelli D, Pozzi B, De Palo G \& Colnaghi MI 1993 The extracellular domain of the C-ErbB-2 oncoprotein is released from tumor cells by proteolytic cleavage. Oncogene 8 2917-2923.

Ranger JJ, Levy DE, Shahalizadeh S, Hallett M \& Muller WJ 2009 Identification of a Stat3-dependent transcription regulatory network involved in metastatic progression. Cancer Research 69 6823-6830. (doi:10.1158/0008-5472.CAN-09-1684)

Riese DJ \& Stern DF 1998 Specificity within the EGF family/ErbB receptor family signaling network. Bioessays 20 41-48. (doi:10.1002/ (SICI) 1521-1878(199801)20:1<41::AID-BIES7>3.0.CO;2-V)

Romond EH, Perez EA, Bryant J, Suman VJ, Geyer CE Jr, Davidson NE, Tan-Chiu E, Martino S, Paik S, Kaufman PA, et al. 2005 Trastuzumab plus adjuvant chemotherapy for operable HER2-positive breast cancer. New England Journal of Medicine 353 1673-1684. (doi:10.1056/NEJMoa052122)

Ross JS, Slodkowska EA, Symmans WF, Pusztai L, Ravdin PM \& Hortobagyi GN 2009 The HER-2 receptor and breast cancer: ten years of targeted anti-HER-2 therapy and personalized medicine. Oncologist 14 320-368. (doi:10.1634/theoncologist.2008-0230)

Sandvig K \& van Deurs B 2002 Transport of protein toxins into cells: pathways used by ricin, cholera toxin and shiga toxin. FEBS Letters 529 49-53. (doi:10.1016/S0014-5793(02)03182-4)

Scaltriti M, Rojo F, Ocana A, Anido J, Guzman M, Cortes J, Di Cosimo S, Matias-Guiu X, Cajal S, Arribas J, et al. 2007 Expression of P95HER2, a truncated form of the HER2 receptor, and response to anti-HER2 therapies in breast cancer. Journal of the National Cancer Institute $\mathbf{9 9}$ 628-638. (doi:10.1093/jnci/djk134)

Scaltriti M, Verma C, Guzman M, Jimenez J, Parra JL, Pedersen K, Smith DJ, Landolfi S, Cajal S, Arribas J, et al. 2009 Lapatinib, a HER2 tyrosine kinase inhibitor, induces stabilization and accumulation of HER2 and potentiates trastuzumab-dependent cell cytotoxicity. Oncogene 28 803-814. (doi:10.1038/onc.2008.432)

Schechter AL, Hung MC, Vaidyanathan L, Weinberg RA, Yang-Feng TL, Francke U, Ullrich A \& Coussens L 1985 The Neu gene: an ErbBhomologous gene distinct from and unlinked to the gene encoding the EGF receptor. Science 229 976-978. (doi:10.1126/ science.2992090)

Schechter AL, Stern DF, Vaidyanathan L, Decker SJ, Drebin JA, Greene MI \& Weinberg RA 1984 The Neu oncogene: an Erb-B-related gene encoding a 185,000-Mr tumour antigen. Nature 312 513-516. (doi:10.1038/312513a0)

Schillaci R, Guzman P, Cayrol F, Beguelin W, Diaz Flaque MC, Proietti CJ, Pineda V, Palazzi J, Frahm I, Charreau EH, et al. 2012 Clinical relevance of ErbB-2/HER2 nuclear expression in breast cancer. BMC Cancer 12 74. (doi:10.1186/1471-2407-12-74)

Schneider MR \& Wolf E 2009 The epidermal growth factor receptor ligands at a glance. Journal of Cellular Physiology 218 460-466. (doi:10.1002/jcp.21635)

Semba K, Kamata N, Toyoshima K \& Yamamoto T 1985 A V-ErbB-related protooncogene, C-ErbB-2, is distinct from the C-ErbB-1/epidermal growth factor-receptor gene and is amplified in a human salivary gland adenocarcinoma. PNAS 82 6497-6501. (doi:10.1073/ pnas.82.19.6497)

Siegel PM, Ryan ED, Cardiff RD \& Muller WJ 1999 Elevated expression of activated forms of Neu/ErbB-2 and ErbB-3 are involved in the induction of mammary tumors in transgenic mice: implications for human breast cancer. EMBO Journal 18 2149-2164. (doi:10.1093/ emboj/18.8.2149)

Sierke SL, Cheng K, Kim HH \& Koland JG 1997 Biochemical characterization of the protein tyrosine kinase homology domain of the ErbB3 (HER3) receptor protein. Biochemical Journal 322 (Part 3) 757-763. (doi:10.1042/bj3220757)

Singh JC, Jhaveri K \& Esteva FJ 2014 HER2-positive advanced breast cancer: optimizing patient outcomes and opportunities for drug development. British Journal of Cancer 111 1888-1898. (doi:10.1038/ bjc.2014.388)

Slamon DJ, Godolphin W, Jones LA, Holt JA, Wong SG, Keith DE, Levin WJ, Stuart SG, Udove J, Ullrich A, et al. 1989 Studies of the HER-2/Neu proto-oncogene in human breast and ovarian cancer. Science 244 707-712. (doi:10.1126/science.2470152)

Slamon DJ, Leyland-Jones B, Shak S, Fuchs H, Paton V, Bajamonde A, Fleming T, Eiermann W, Wolter J, Pegram M, et al. 2001 Use of chemotherapy plus a monoclonal antibody against HER2 for metastatic breast cancer that overexpresses HER2. New England Journal of Medicine 344 783-792. (doi:10.1056/ NEJM200103153441101)

Song B, Wang C, Liu J, Wang X, Lv L, Wei L, Xie L, Zheng Y \& Song X 2010 MicroRNA-21 regulates breast cancer invasion partly by http://erc.endocrinology-journals.org

DOI: 10.1530/ERC-16-0360
(C) 2016 Society for Endocrinology Printed in Great Britain 
targeting tissue inhibitor of metalloproteinase 3 expression. Journal of Experimental and Clinical Cancer Research 29 29. (doi:10.1186/17569966-29-29)

Stern HM 2012 Improving treatment of HER2-positive cancers: opportunities and challenges. Science Translational Medicine 4 127rv2. (doi:10.1126/scitranslmed.3001539)

Tan M, Jing T, Lan KH, Neal CL, Li P, Lee S, Fang D, Nagata Y, Liu J, Arlinghaus R, et al. 2002 Phosphorylation on tyrosine-15 of P34(Cdc2) by ErbB2 inhibits P34(Cdc2) activation and is involved in resistance to taxol-induced apoptosis. Molecular Cell 9 993-1004. (doi:10.1016/S1097-2765(02)00510-5)

Tao RH \& Maruyama IN 2008 All EGF(ErbB) receptors have preformed homo- and heterodimeric structures in living cells. Journal of Cell Science 121 3207-3217. (doi:10.1242/jcs.033399)

Tsai B, Ye Y \& Rapoport TA 2002 Retro-translocation of proteins from the endoplasmic reticulum into the cytosol. Nature Reviews Molecular Cell Biology 3 246-255. (doi:10.1038/nrm780)

Tzahar E, Waterman H, Chen X, Levkowitz G, Karunagaran D, Lavi S, Ratzkin BJ \& Yarden Y 1996 A hierarchical network of interreceptor interactions determines signal transduction by neu differentiation factor/neuregulin and epidermal growth factor. Molecular and Cellular Biology 16 5276-5287. (doi:10.1128/MCB.16.10.5276)

Ursini-Siegel J, Hardy WR, Zuo D, Lam SH, Sanguin-Gendreau V, Cardiff RD, Pawson T \& Muller WJ 2008 ShcA signalling is essential for tumour progression in mouse models of human breast cancer. EMBO Journal 27 910-920. (doi:10.1038/emboj.2008.22)

Vazquez-Martin A, Oliveras-Ferraros C, Cufi S, Del Barco S, MartinCastillo B \& Menendez JA 2011 Lapatinib, a dual HER1/HER2 tyrosine kinase inhibitor, augments basal cleavage of HER2 extracellular domain (ECD) to inhibit HER2-driven cancer cell growth. Journal of Cellular Physiology 226 52-57. (doi:10.1002/ jcp.22333)

Venturutti L, Romero LV, Urtreger AJ, Chervo MF, Cordo Russo RI, Mercogliano MF, Inurrigarro G, Pereyra MG, Proietti CJ, Izzo F, et al. 2015 Stat3 regulates ErbB-2 expression and co-opts ErbB-2 nuclear function to induce MiR-21 expression, PDCD4 downregulation and breast cancer metastasis. Oncogene 29 1468-1485. (doi:10.1038/ onc.2015.281)

Wang SC, Lien HC, Xia W, Chen IF, Lo HW, Wang Z, Ali-Seyed M, Lee D F, Bartholomeusz G, Ou-Yang F, et al. 2004 Binding at and transactivation of the COX-2 promoter by nuclear tyrosine kinase receptor ErbB-2. Cancer Cell 6 251-261. (doi:10.1016/j. ccr.2004.07.012)

Wang YN \& Hung MC 2012 Nuclear functions and subcellular trafficking mechanisms of the epidermal growth factor receptor family. Cell and Bioscience 2 13. (doi:10.1186/2045-3701-2-13)

Wang YN, Lee HH, Lee HJ, Du Y, Yamaguchi H \& Hung MC 2012 Membrane-bound trafficking regulates nuclear transport of integral epidermal growth factor receptor (EGFR) and ErbB-2. Journal of Biological Chemistry 287 16869-16879. (doi:10.1074/jbc. M111.314799)

Wang YN, Yamaguchi H, Hsu JM \& Hung MC 2010a Nuclear trafficking of the epidermal growth factor receptor family membrane proteins. Oncogene 29 3997-4006. (doi:10.1038/onc.2010.157)

Wang YN, Yamaguchi H, Huo L, Du Y, Lee HJ, Lee HH, Wang H, Hsu JM \& Hung MC 2010b The translocon Sec61beta localized in the inner nuclear membrane transports membrane-embedded EGF receptor to the nucleus. Journal of Biological Chemistry 285 38720-38729. (doi:10.1074/jbc.M110.158659)

Warri AM, Isola JJ \& Harkonen PL 1996 Anti-oestrogen stimulation of ERBB2 ectodomain shedding from BT-474 human breast cancer cells with ERBB2 gene amplification. European Journal of Cancer 32A 134-140. (doi:10.1016/0959-8049(95)00550-1)

Waugh MG \& Hsuan JJ 2001 EGF receptors as transcription factors: ridiculous or sublime? Nature Cell Biology 3 E209-E211. (doi:10.1038/ ncb0901-e209)

Williams CC, Allison JG, Vidal GA, Burow ME, Beckman BS, Marrero L \& Jones FE 2004 The ERBB4/HER4 receptor tyrosine kinase regulates gene expression by functioning as a STAT5A nuclear chaperone. Journal of Cell Biology 167 469-478. (doi:10.1083/ jcb.200403155)

Xia W, Liu LH, Ho P \& Spector NL 2004 Truncated ErbB2 receptor (P95ErbB2) is regulated by heregulin through heterodimer formation with ErbB3 yet remains sensitive to the dual EGFR/ErbB2 kinase inhibitor GW572016. Oncogene 23 646-653. (doi:10.1038/sj. onc.1207166)

Xie Y \& Hung MC 1994 Nuclear localization of P185neu tyrosine kinase and its association with transcriptional transactivation. Biochemical and Biophysical Research Communications 203 1589-1598. (doi:10.1006/bbrc.1994.2368)

Xu W, Yuan X, Beebe K, Xiang Z \& Neckers L 2007 Loss of Hsp90 association up-regulates Src-dependent ErbB2 activity. Molecular and Cellular Biology 27 220-228. (doi:10.1128/MCB.00899-06)

Yakes FM, Chinratanalab W, Ritter CA, King W, Seelig S \& Arteaga CL 2002 Herceptin-induced inhibition of phosphatidylinositol-3 kinase and Akt is required for antibodymediated effects on P27, cyclin D1, and antitumor action. Cancer Research 62 4132-4141.

Yamamoto T, Ikawa S, Akiyama T, Semba K, Nomura N, Miyajima N, Saito T \& Toyoshima K 1986 Similarity of protein encoded by the human C-Erb-B-2 gene to epidermal growth factor receptor. Nature 319 230-234. (doi:10.1038/319230a0)

Yan LX, Huang XF, Shao Q, Huang MY, Deng L, Wu QL, Zeng YX \& Shao JY 2008 MicroRNA MiR-21 overexpression in human breast cancer is associated with advanced clinical stage, lymph node metastasis and patient poor prognosis. RNA 14 2348-2360. (doi:10.1261/rna.1034808)

Yang CH, Yue J, Pfeffer SR, Handorf CR \& Pfeffer LM 2011 MicroRNA MiR-21 regulates the metastatic behavior of B16 melanoma cells. Journal of Biological Chemistry 286 39172-39178. (doi:10.1074/jbc. M111.285098)

Yarden Y \& Sliwkowski MX 2001 Untangling the ErbB signalling network. Nature Reviews Molecular Cell Biology 2 127-137. (doi:10.1038/35052073)

Zhu S, Wu H, Wu F, Nie D, Sheng S \& Mo YY 2008 MicroRNA-21 targets tumor suppressor genes in invasion and metastasis. Cell Research 18 350-359. (doi:10.1038/cr.2008.24)

Zuo T, Wang L, Morrison C, Chang X, Zhang H, Li W, Liu Y, Wang Y, Liu X, Chan MW, et al. 2007 FOXP3 is an X-linked breast cancer suppressor gene and an important repressor of the HER-2/ErbB2 oncogene. Cell 129 1275-1286. (doi:10.1016/j. cell.2007.04.034)

Received in final form 3 October 2016

Accepted 6 October 2016

Accepted Preprint published online 7 October 2016 http://erc.endocrinology-journals.org DOI: 10.1530/ERC-16-0360
(C) 2016 Society for Endocrinology Printed in Great Britain
Published by Bioscientifica Ltd 